\title{
Ulnar Sided Wrist Pain; Consider Pisotriquetral (PT) Pathology
}

\author{
M Van Hal* and AH Schuurman \\ Department of Plastic and Reconstructive Surgery, University Medical Centre Utrecht, Netherlands
}

Submission: December 12, 2017; Published: December 19, 2017

*Corresponding author: M Van Hal, Department of Plastic and Reconstructive Surgery, University Medical Centre Utrecht, Heidelberglaan, Netherlands, Email: M.vanHal-4@umcutrecht.nl

\begin{abstract}
Pisotriquetral pathology is an important reason for ulnar-sided wrist pain and is frequently overlooked. Cadaveric studies illustrate a high prevalence in the older population. Physical examination is important in diagnosing PT pathology. X-rays and CT-scans can assist in diagnosing PT pathology. Splinting and steroid injections are the treatment of first choice in the absence of PT arthrosis. In case of persistent pain or arthrosis, pisiformectomy should be performed. Pisiformectomy does not cause loss in range of motion, grip strength or carpal instability
\end{abstract}

Keywords: Ulnar-sided wrist pain; Isotriquetral pathology; Pisotriquetral arthrosis; Flexor carpi ulnaris tendinitis; Flexor carpi ulnarisenthesopathy

\section{Introduction}

PT pathology is one of the 26 reasons for ulnar sided wrist pain. Several papers have been published regarding the fact that PT pathology is easily overlooked when considering the differential diagnosis for ulnar sided wrist pain [1,2]. It is our belief that, despite the attention that has been given to this subject, this diagnosis is still frequently missed. Therefore, we would like to emphasize the importance of considering PT pathology in patients with ulnar sided wrist pain.

\section{Clinical Case}

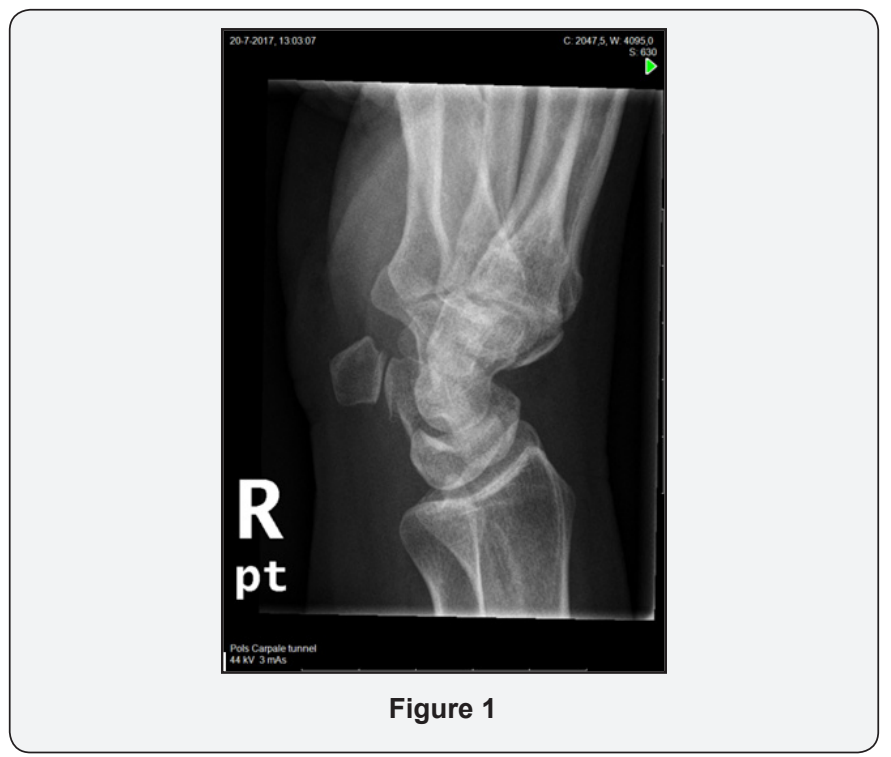

A 50-year old female visited our outpatient clinic with ulnar sided wrist pain since 12 months on the right hand side. She could not remember any trauma. Ulnar deviation was painful. Palpation of the PT joint and FCU tendon was painful. A PT $\mathrm{X}$-ray view demonstrated no signs of arthrosis (Figure 1). She was treated with a steroid injection near the insertion of the FCU on the pisiform for FCU tendinitis. Furthermore, she used a splint for six weeks. After six weeks her pain persisted, and grinding of the PT joint was painful. Under plexus anesthesia, a pisiformectomy was performed. Although not clear on X-rays, there was severe cartilage damage on the surface of the PT joint (Figure 2). A dressing was applied for 24 hours postoperatively. After removal of the dressing she resumed her normal daily activities. After 4 weeks, she reported complete pain relief.

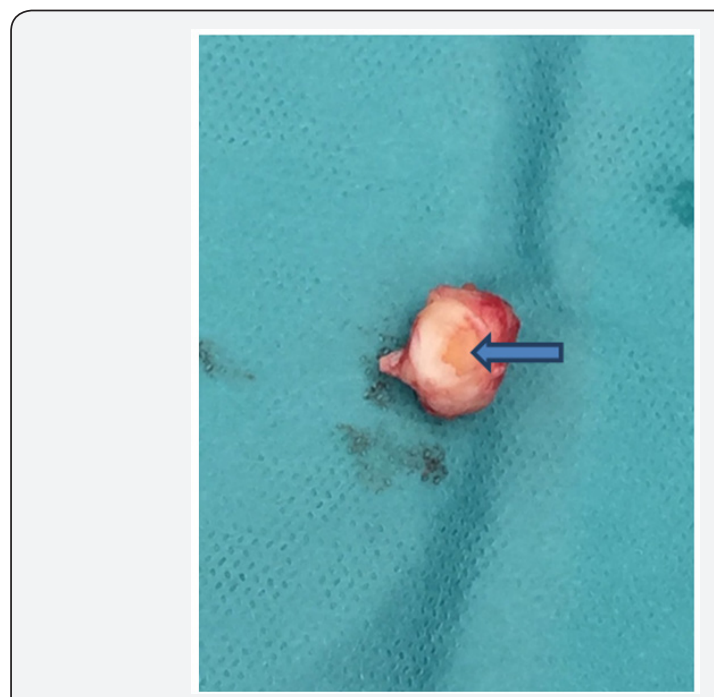

Figure 2: Arrow indicating absent cartilage 


\section{Etiology}

The pisiform is a sesamoid bone incorporated in the flexor carpi ulnaris tendon. Under normal circumstances, multiple dynamic forces act on the pisiform and cause considerable motion between pisiform and triquetrum [1,3,4,5]. After ST arthrosis, PT arthrosis is the most common form of degeneration of the carpus [6]. A cadaveric study by Kofman et al showed an impressive prevalence of $9 / 10$ osteoarthritic PT joints in the older population [7]. Apart from idiopathic osteoarthritis in the elderly, PT pathology can also be encountered in cases of overuse, fractures, rheumatoid arthritis, impingement syndromes and in post-surgical settings after carpal tunnel release known as pillar pain $[1,8,9,10]$

\section{Diagnosis}

Symptoms are ulnar sided wrist pain which increases with flexion and/or ulnar deviation of the wrist and thumb opposition. When examining the patient, direct pressure upon the pisiform is painful. The pisiform tracking test, also known as the grind test, is probably the most useful tool to assess PT osteoarthritis. In this case, the wrist is flexed and the pisiform is fixed between thumb and second finger of the examiner. is the pisoforme bone rotated over the triquetral surface ulnarly and radially. PT joint osteoarthritis should be considered in case of a painful tracking test. Unfortunately there is no gold standard in diagnosing PT osteoarthritis. There is also no radiologic classification available for PT osteoarthritis. When evaluating the PT joint on x-ray, it is of importance to obtain either a semi-supinated view or Garraud view to assess indicators of PT arthrosis. Both sides must be evaluated osteophytes. For example, narrowing of the joint space, sclerosis, decentering of the pisiform and calcification of the FCU tendon can be determined $[2,11]$

Ten Berg et al. [11] illustrated that Joint Space Width (JSW) in subjects with operatively diagnosed PT arthrosis is narrowed to $<0.1 \mathrm{~mm}$ as opposed to normal PT JSW of at least $0.8 \mathrm{~mm}$ on CT scans. Ultrasound investigation could illustrate joint effusion or synovial thickening [11]. Based on a discrepancy of radiologic findings to macroscopy and microscopy, Kofman et al. [7] illustrated that radiographs are not sufficient as the only diagnostic tool in suspected pathology of the PT joint. In the absence of a valid diagnostic tool, it is our opinion that meticulous clinical evaluation is of importance in diagnosing PT joint pathology.

\section{Treatment}

Non-operative treatments includephysiotherapy, non-steroid anti-inflammatory drugs, intra-articular steroid injections and splinting with the wrist in 20 degrees of flexion en ulnar deviation. In cases where conservative treatment does not meet the desired effect, pisiformectomy should be considered. Several papers investigating patients who underwent pisiformectomy for PT osteoarthritis demonstrated that almost complete pain relief was achieved after a mean of 7.4 weeks postoperatively. Mean VAS scores reduced significantly without observing loss in wrist range of motion or grip strength $[10,13,12]$.

\section{Conclusion}

PT joint osteoarthritis is a common diagnosis that should not be overlooked in patients presenting with ulnar sided wrist pain. $\mathrm{X}$-rays, CT-scans and ultrasounds can support the diagnosis but are not sufficient as the only diagnostic tool. Clinical investigation should be the cornerstone of the diagnosis. In cases where nonoperative treatment is not effective, pisiformectomy should be performed. Almost complete pain relief can be obtained without compromising range of motion or grip strength.

\section{Conflict of Interest}

No economic interest or any conflict of interest can be declared.

\section{References}

1. Moraux Lefebvre G, Pansini V, Aucourt J, Vandenbussche L, et al. (2014) Pisotriquetral joint disorders: an under-recognized cause of ulnar side wrist pain. Skeletal Radiol 43(6): 761-773.

2. Atsuya Watanabe, Souza F, Vezeridis PS, Blazar P, Yoshioka H, (2010) Ulnar-sided wrist pain. II. Clinical imaging and treatment. Skeletel Radiol 39(9): 837-857.

3. May O (1996) The pisiform bone: sesamoid or carpal bone? Ann chir Main Memb Super 15(4): 265-271.

4. Pevny (1995) Ligamentous and tendinous support of the pisiform, anatomix and biomechanical study. J Hand Surg (Am) 20(2): 299-304

5. Yamaguchi, Viegas SF, Patterson RM (1998) Anatomix study of the pisotriquetral joint: ligament anatomy and cartilaginous change. J Hand Surg Am 23(4): 600-606.

6. Fischer E (1988) Piso-triquetral arthrosis and the so-called pisiform secundarium. Radiology 28(7): 338-344.

7. Kofman KE, Schuurman AH, Mulder MC, Verlinde SA, Gierman LM, van Diest PJ (2014) The pisotriquetral Joint: Osteoarthritis and Enthesopathy. J Hand Microsurg 6(1): 18-25.

8. Hikono Aiki, Wada T, Yamashita T (2006) Pisotriquetral Arthrosis After Triquetral Malunion: A Case report. J Hand Surg Am 31(7): 1157-1159.

9. Boyce, Harden JL (2010) Pisiform fracture: an uncommon wrist injury. BMJ Case Rep 2010: 2132.

10. Lautenbach, Eisenschenk A, Langner I, Arntz U, Millrose M (2013) Comparison of clinical Results after Pisiformectomy in Patients with Rheumatic Versus Posttraumatic Osteoarthritis. Orthopedics 36(10): 31239-31243.

11. Paul ten Berg Heeg E, Strackee SD, Streekstra GJ (2017) Joint space Narrowing in Patients with Pisotriquetral Osteoarthritis. Hand 2017 12(5): 490-492.

12. Campion Goad A, Rayan G, Porembski M (2014) Pisiform Excision for Pisotriquetral Instability and Arthritis. J Hand surg Am. 39(7): 12511257.

13. Lam KS, Woodbridge S, Burke FD (2003) Wirst function after excision of the pisiform. J Hand Surg (Britisch and European Volume) 28(1): 69-72. 
This work is licensed under Creative Commons Attribution 4.0 License DOI: $10.19080 /$ OROAJ.2017.09.555768

\section{Your next submission with Juniper Publishers will reach you the below assets}

- Quality Editorial service

- Swift Peer Review

- Reprints availability

- E-prints Service

- Manuscript Podcast for convenient understanding

- Global attainment for your research

- Manuscript accessibility in different formats

( Pdf, E-pub, Full Text, Audio)

- Unceasing customer service

Track the below URL for one-step submission https://juniperpublishers.com/online-submission.php 